\title{
Optimization of Residual Stress Measurement Conditions for a 2D Method Using X-ray Diffraction and Its Application for Stainless Steel Treated by Laser Cavitation Peening
}

\author{
Hitoshi Soyama ${ }^{1, * \mathbb{D}}$, Chieko Kuji $^{2}$, Tsunemoto Kuriyagawa ${ }^{2}\left(\mathbb{D}\right.$, Christopher R. Chighizola $^{3}$ and \\ Michael R. Hill ${ }^{3}$ (D) \\ 1 Department of Finemechanics, Tohoku University, Sendai 980-8579, Japan \\ 2 Department of Mechanical Systems Engineering, Tohoku University, Sendai 980-8579, Japan; \\ kuji.shinkou@gmail.com (C.K.); tkuri@tohoku.ac.jp (T.K.) \\ 3 Department of Mechanical and Aerospace Engineering, University of California Davis, \\ Davis, CA 95616, USA; crchighizola@ucdavis.edu (C.R.C.); mrhill@ucdavis.edu (M.R.H.) \\ * Correspondence: soyama@mm.mech.tohoku.ac.jp; Tel.: +81-22-795-6891
}

Citation: Soyama, H.; Kuji, C.; Kuriyagawa, T.; Chighizola, C.R.; Hill, M.R. Optimization of Residual Stress Measurement Conditions for a 2D Method Using X-ray Diffraction and Its Application for Stainless Steel Treated by Laser Cavitation Peening. Materials 2021, 14, 2772. https:// doi.org/10.3390/ma14112772

Academic Editors: Thomas

Walter Cornelius and

Souren Grigorian

Received: 23 April 2021

Accepted: 20 May 2021

Published: 24 May 2021

Publisher's Note: MDPI stays neutral with regard to jurisdictional claims in published maps and institutional affiliations.

Copyright: (c) 2021 by the authors. Licensee MDPI, Basel, Switzerland. This article is an open access article distributed under the terms and conditions of the Creative Commons Attribution (CC BY) license (https:// creativecommons.org/licenses/by/ $4.0 /)$.

\begin{abstract}
As the fatigue strength of metallic components may be affected by residual stress variation at small length scales, an evaluation method for studying residual stress at sub-mm scale is needed. The $\sin ^{2} \psi$ method using X-ray diffraction (XRD) is a common method to measure residual stress. However, this method has a lower limit on length scale. In the present study, a method using at a 2D XRD detector with $\omega$-oscillation is proposed, and the measured residual stress obtained by the 2D method is compared to results obtained from the $\sin ^{2} \psi$ method and the slitting method. The results show that the $2 \mathrm{D}$ method can evaluate residual stress in areas with a diameter of $0.2 \mathrm{~mm}$ or less in a stainless steel with average grain size of $7 \mu \mathrm{m}$. The 2D method was further applied to assess residual stress in the stainless steel after treatment by laser cavitation peening (LCP). The diameter of the laser spot used for LCP was about $0.5 \mathrm{~mm}$, and the stainless steel was treated with evenly spaced laser spots at 4 pulses $/ \mathrm{mm}^{2}$. The 2D method revealed fluctuations of LCP-induced residual stress at sub-mm scale that are consistent with fluctuations in the height of the peened surface.
\end{abstract}

Keywords: residual stress; X-ray diffraction; laser cavitation peening; pulse laser

\section{Introduction}

As residual stress is one of the most important factors related to the fatigue strength of metallic materials [1-8], it is worth measuring the residual stress in local areas subject to fatigue crack nucleation. It is well known that conventional welding causes tensile residual stress near the welded line due to the heat-affected zone (HAZ) [9-12]. Friction stir welding (FSW) also generates tensile residual stress near the FSW region [13-18], as FSW produces stirring and a thermo-mechanically affected zone. Residual stress is one of the key factors for mechanical surface treatments such as shot peening (SP) [19]. Laser peening can also improve fatigue properties by introducing compressive residual stress [20-23]. As the distribution of the residual stress of conventional welding and the FSWed part drastically changes with distance from the welding line, the residual stress of the laser-peened surface is also distributed with a laser spot size of the mm-order. One of the conventional methods used to evaluate the residual stress is X-ray diffraction. As the size of the measured area using X-ray diffraction is similar to that of the distribution of the residual stress of the welding part and/or the laser-peened surface in sub-millimeter order, it is necessary to improve the accuracy of residual stress measurements by using X-ray diffraction. Note that the most important factor of the stresses measurement accuracy in local area using X-ray diffraction is the number of the grains.

The $\sin ^{2} \psi$ method is the most popular method for evaluating the residual stress of polycrystal metals using X-ray diffraction [24], and a 2D method using a two-dimensional 
detector has been developed [25]. Regarding JSMS standard, $3 \times 10^{5}$ to $6 \times 10^{5}$ grains is required for the $\sin ^{2} \psi$ method. Each method is based on its own theory, and each has advantages and disadvantages. For example, in the case of the $\sin ^{2} \psi$ method, a simple goniometer is sufficient to evaluate the residual stress. On the other hand, the 2D method can evaluate the 3D stress state, but a highly accurate multi-axis goniometer is needed. The great advantage of using a 2D detector is that the Debye ring can be evaluated by interpolation and extrapolation. Namely, the 2D method using a 2D detector could be used to evaluate residual stress of very small area and/or coarse grain. A 2D method with specimen oscillation by moving the detector in the direction orthogonal to $\theta$-direction was proposed to obtain better Debye ring in the reference [26], but the obtained result was not compared with the result obtained using the other method. One way to evaluate residual stress measurements using X-ray diffraction is to compare them with mechanical relaxation method such as a slitting method [27] and/or a hole drilling method [28]. The slitting method is relatively easy to perform, can be performed quickly, and provides excellent repeatability, which makes it very useful for actual laboratory residual stress measurements [27]. As the experimental deviation of the slitting method was smaller than that of the hole drilling method [29], the slitting method was chosen in the present experiment.

As mentioned above, laser peening introduces compressive residual stress and enhances the fatigue properties [20-23]. Y. Sano et al. measured the residual stress distribution with depth for stainless steel SUS304 and demonstrated an improvement in fatigue strength by laser peening without protective coating [21]. In the case of laser peening with coating [20,22], coating or tapes such as black polymer tape or metal foil is pasted on material to control laser energy absorption and prevent the surface from melting. The distributions of residual stress were precisely measured, but fluctuations due to the laser spot were not observed [30,31]. The distribution of changes in residual stress with depth was precisely measured, but there was no information provided for the distribution on the surface [32,33]. On the other hand, in the case of the numerical simulation, residual stress distributions due to laser spots were clearly observed [6,34-36]. Recently, the patterns of residual stress on the surface due to laser spots were also observed $[37,38]$. G. Xu et al. measured the residual stress of SUS316L by the $\sin ^{2} \psi$ method, in which the diameter of the measured area was $2 \mathrm{~mm}$ with a $0.5 \mathrm{~mm}$ step; the laser spot was $3 \times 3 \mathrm{~mm}^{2}$; the overlapping rates were $30 \%$, $50 \%$ and $70 \%$; and the cyclic pattern of the residual stress was obtained [37]. X. Pan et al. measured the residual stress of Ti6Al4V by the $\sin ^{2} \psi$ method, in which the diameter of the measuring area was $2 \mathrm{~mm}$ with a $1 \mathrm{~mm}$ step, the laser spot was $2.4 \mathrm{~mm}$, the overlapping rate was $40 \%$ and a cyclic pattern due to laser spots was not observed in the distribution of residual stress [39]. Using a synchrotron, Y. Sano et al. measured the distribution of the residual stress crossing over a single laser spot with $1 \mathrm{D}$ line irradiation by measuring an area of $0.2 \mathrm{~mm}$ in diameter; the laser spot was about $1 \mathrm{~mm}$ in diameter and the authors reported the tensile residual stress due to the laser spot [38]. It was determined by numerical simulation that the crack propagation was affected by the residual stress distribution due to laser peening $[40,41]$; therefore, the precise distribution of the residual stress had to be determined. Figure 1 shows the typical pattern of a fractured fatigue specimen of a stainless steel (a) non-peened specimen and (b) laser-peened specimen [23]. As shown in Figure 1b, the fatigue crack of the laser-peened specimen propagated nearly straight compared with that of the non-peened one, in which several cracks were propagated in parallel due to the increase of the hardness near the crack tips by plastic deformation. The distribution of residual stress of laser peened specimen. The distribution of residual stress of the laser peened specimen could be one of the reasons for crack propagation. Considering a previous report [38], the measurement of the residual stress in a submillimeter-order area is required. Thus, a method that can measure residual stress at a submillimeter level using a conventional X-ray diffraction apparatus is needed.

This paper consists of two parts. The first half reveals the optimization of measuring the condition of the 2D method using a two-dimensional detector for residual stress 
measurements to evaluate the surface modification layer compared with the mechanical method, i.e., the slitting method [27], and the $\sin ^{2} \psi$ method [24]. The second half demonstrates the residual stress measurement of the peened specimen by laser cavitation peening using the proposed 2D method.

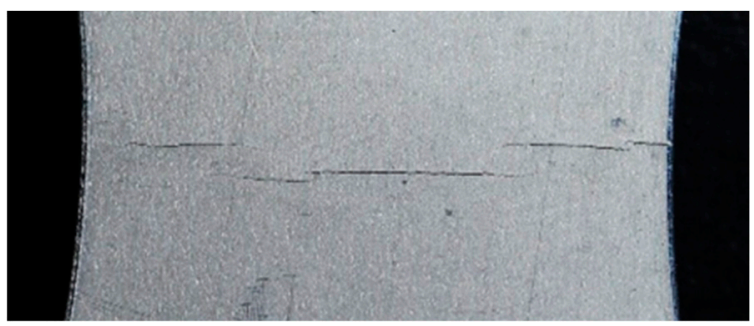

(a)

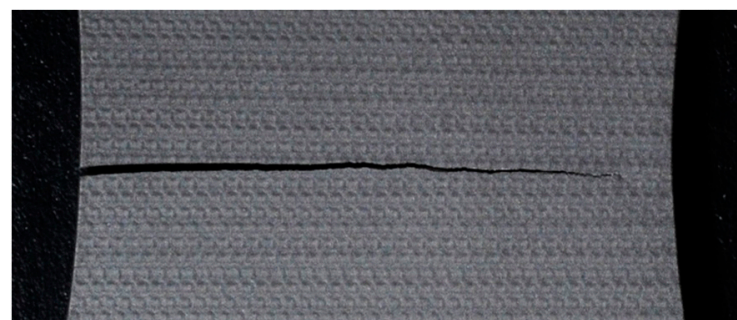

(b)

Figure 1. Aspect of a fractured fatigue specimen of stainless steel. (a) Non-peened specimen $\left(\sigma_{a}=301 \mathrm{MPa}, N_{f}=7.8 \times 10^{5}\right)$; (b) specimen treated by laser cavitation peening $\left(\sigma_{a}=308 \mathrm{MPa}, N_{f}=4.8 \times 10^{6}\right)$.

\section{Experimental Apparatus and Procedures}

\subsection{Peening Systems}

To prepare specimens with compressive residual stress, cavitation peening (CP) using a cavitating jet (see Figure 2) and laser cavitation peening (LCP) using a pulse laser (see Figure 3) were applied. In the case of $\mathrm{CP}$, a high-speed water jet was injected into a waterfilled chamber. The cavitating conditions were the same as those in a previous paper [8]; the injection pressure of the jet was $30 \mathrm{MPa}$, the diameter of the nozzle $d$ was $2 \mathrm{~mm}$ and the standoff distance was $222 \mathrm{~mm}$. To enhance the peening intensity, the nozzle had a cavitator with a diameter $d_{c}$ of $3 \mathrm{~mm}$ [42] and an outlet bore with a diameter $D$ and length $L$ of 16 and $16 \mathrm{~mm}$, respectively [43]. The specimen was installed in the recess. In the case of LCP, a Nd:YAG (Nd: $\left.\mathrm{Y}_{3} \mathrm{Al}_{5} \mathrm{O}_{12}\right)$ laser with Q-switch was used to generate laser cavitation [12]. The repetition frequency of the pulse laser was $10 \mathrm{~Hz}$. The used wavelength was $1064 \mathrm{~nm}$. The pulse laser was focused onto the specimen, which was placed in a water-filled glass chamber. The standoff distance in the air $s_{a}$ and in water $s_{w}$ was optimized by measuring the peening intensity [12]. The specimen based the stage was moved perpendicularly to the direction of the laser axis by the stepping motors.

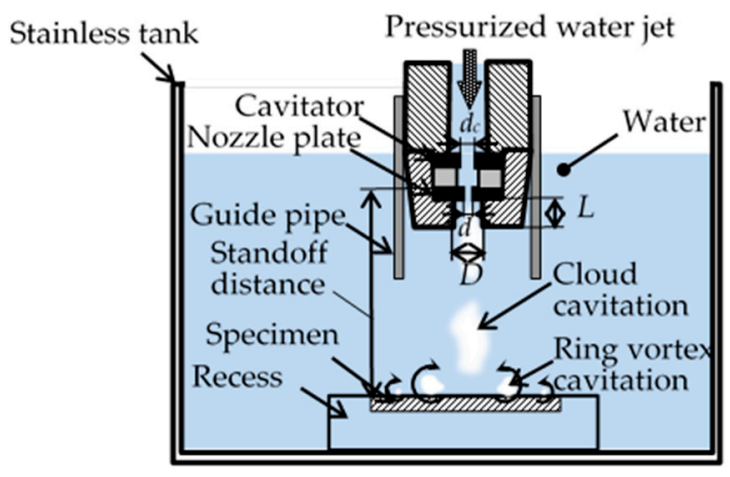

Figure 2. Schematic diagram of cavitation peening (CP) using a cavitating jet.

As the backside surface of the peened plate had compressive residual stress [44], a recirculating shot peening (SP) system accelerated by a water jet [45] was used for the peening. Note that compressive residual stress was introduced onto the backside surface, but the grain size on the back side was not affected, as the backside surface was not peened. At SP, the shots were installed a chamber, whose diameter was $54 \mathrm{~mm}$, and accelerated by the water jet through three holes with a diameter of $0.8 \mathrm{~mm}$. The diameter and the number of the shots were $3.2 \mathrm{~mm}$ and 500, respectively. The injection pressure of the water jet was 
$12 \mathrm{MPa}$. The distance from the nozzle to the specimen surface was $50 \mathrm{~mm}$. To avoid a loss of shots, the specimen was set in the recess.

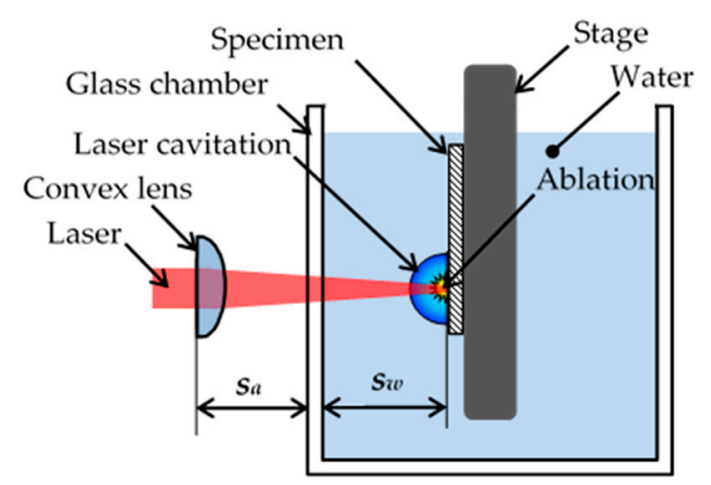

Figure 3. Schematic diagram of cavitation peening using a pulse laser, i.e., laser cavitation peening (LCP).

\subsection{Material}

The tested material was austenitic stainless steel, Japanese Industrial Standards JIS SUS316L. Four different specimens were used, as shown in Table 1. All specimens were made from plates 2, 3 and $6 \mathrm{~mm}$ in thickness, respectively, and all the plates featured a No. 2B surface finish accomplished by temper rolling. Specimen A was used to measure the residual stress of the peened side by the 2D method compared with the slitting method and $\sin ^{2} \psi$ method. Specimens A, B and C were used to optimize the measuring conditions of the 2D method. Specimen $\mathrm{D}$ was used to demonstrate the effect of the laser spot on the residual stress distribution. During LCP, the surface was laser and the outermost surface showed tensile residual stress; the surface was then removed by electrochemical polishing. The peening intensity of $\mathrm{CP}, \mathrm{SP}$ and LCP was controlled based on processing time per unit length, processing time and pulse density, respectively. The processing time per unit length of specimen A was chosen based on the values in the reference [8]. To introduce large compressive residual stress into the specimen, $100 \mathrm{pulses} / \mathrm{mm}^{2}$ pulse density and $6 \mathrm{~mm}$ thickness were chosen for specimen B. Considering the results of the preliminary experiment by measuring the residual stress, $30 \mathrm{~s}$ and $3 \mathrm{~mm}$ thickness were chosen for specimen C. For specimen D, the pulse density of 4 pulses $/ \mathrm{mm}^{2}$ was optimized by measuring the fatigue life changes based on pulse density.

Table 1. Specimens for residual stress measurements.

\begin{tabular}{cccccc}
\hline Symbol & Peening Method & Peening Intensity & Thickness & Measured Side & Electrochemical Polishing \\
\hline A & Cavitation peening CP & $8 \mathrm{~s} / \mathrm{mm}$ & $2 \mathrm{~mm}$ & Peened side & None \\
\hline B & Laser cavitation peening LCP & 100 pulses $/ \mathrm{mm}^{2}$ & $6 \mathrm{~mm}$ & Peened side & $39 \mu \mathrm{m}$ \\
\hline C & Shot peening SP & $30 \mathrm{~s}$ & $3 \mathrm{~mm}$ & Back side & None \\
\hline D & Laser cavitation peening LCP & 4 pulses $/ \mathrm{mm}^{2}$ & $2 \mathrm{~mm}$ & Peened side & $33 \mu \mathrm{m}$ \\
\hline
\end{tabular}

As mentioned above, the number of grains in the measurement area is important factor for the accuracy of the stresses using X-ray diffraction method. The average grain size, i.e., spatial diameter [46] and the grain size that occupied $50 \%$ of the area $d_{N}$ were measured. The $d_{N}$ was obtained by the following procedure. The area $A_{i}$ of each grain was measured and they were sorted from small value to large value, then the cumulated area $A_{C}$ was calculated as follows.

$$
A_{C}=\sum_{i=1}^{N} A_{i}
$$


when the number $N$ at $A_{C} / A=50 \%$ was obtained, $d_{N}=2 \sqrt{A_{N} / \pi}$ was defined as the grain size that occupied $50 \%$. Here, $A$ was test area. 300 grains were measured in the present experiment.

Figure 4 illustrates a schematic diagram of specimen $\mathrm{D}$ and the coordinates of the residual stress with the scanning direction of the laser. The specimen was moved at $5 \mathrm{~mm} / \mathrm{s}$, and the reputation frequency of the laser was $10 \mathrm{~Hz}$. Then, the specimen was stepped at $0.5 \mathrm{~mm}$, as shown in Figure 4. The positional relationship of the laser spots in each row was different for each row as shown in Figure 4, as the stepping motors and pulse laser were not synchronized. Note that the rolling direction was $y$-direction in Figure 4 .

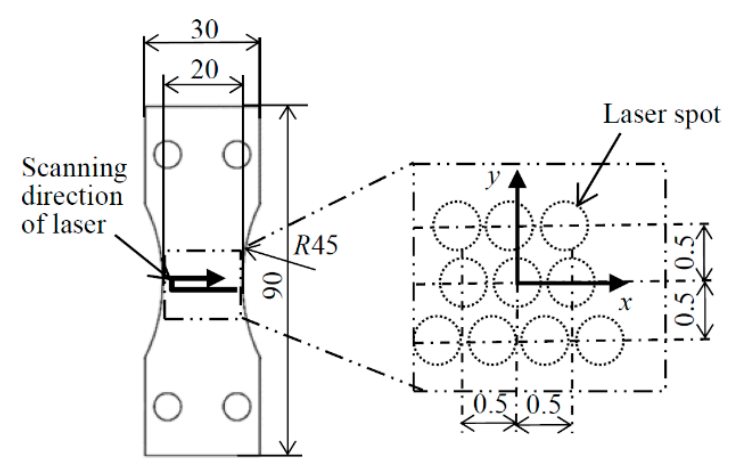

Figure 4. Schematic diagram of specimen D treated by laser cavitation peening and the coordinates for residual stress measurement.

\subsection{Residual Stress Measurement}

To confirm the compressive residual stress of specimen A introduced by cavitation peening, the residual stress was measured using the slitting method [27]. The slitting was done using a wire electric discharge machine (EDM, Sodick, Chicago, IL, USA), and the residual stress was evaluated from the strain obtained by the strain gage. The diameter of the wire was $0.254 \mathrm{~mm}$ and the gage length of the strain gage was $0.81 \mathrm{~mm}$. The distribution of the residual stress with depth under the surface was obtained by using the recorded strain and solving an inverse problem following the procedure in the reference [15]. In the present paper, slitting of $0.0254 \mathrm{~mm}$ in depth was used as the reference value. The distribution of the residual stress with depth and more details on the slitting method can be found in the reference [8].

To measure the residual stress by X-ray diffraction, an XRD system (Bruker Japan K. K., Tokyo, Japan) with a two-dimensional position sensitive proportional counter (2D-PSPC) was used. The same system was used for the $\sin ^{2} \psi$ method [24] and 2D method [47]. The schematic diagram and coordinates $\theta, \psi, \omega, \chi, \varphi$ of the XRD system with 2D-PSPC are shown in Figure 5. The $\mathrm{K} \alpha \mathrm{X}$-rays from a Cr-tube operating at $35 \mathrm{kV}$ and $40 \mathrm{~mA}$ were used. The used diffracted plane was $\gamma$-Fe (2 20$)$, and the diffraction angle without strain was $128^{\circ}$. In the residual stress analysis for both the $\sin ^{2} \psi$ method and the 2D method, Relevant software (Leptos ver 7.9, Bruker Japan K. K., Tokyo, Japan) was used. The used Young's modulus and Poisson ratio were $191.975 \mathrm{GPa}$ and 0.3 , respectively. To investigate the effects of the measuring area, five different collimators with diameters of $0.1460,0.3,0.5,0.5724$ and $0.8 \mathrm{~mm}$ were used. The 0.1460 and $0.5724 \mathrm{~mm}$ collimators were of the total reflection type, and the other collimators were of the double-holed type. Tables 2 and 3 show the measuring conditions and analyzed areas of $\mathrm{X}$-ray diffraction obtained using each method based on the standard method [24] and the previous report [26]. Under both the $\sin ^{2} \psi$ method and the 2D method, 24 frames were measured. In the case of the $\sin ^{2} \psi$ method, the X-ray diffraction profile obtained an accumulating X-ray diffraction of $\chi=85-95^{\circ}$, and diffracted peaks $2 \theta$ were obtained at each $\psi$. Then, the residual stress was calculated from the $\sin ^{2} \psi-2 \theta$ diagram. To eliminate the $\psi$ split, $+\psi$ and $-\psi$ were measured for each $x$ and $y$ direction. At the $\sin ^{2} \psi$ method, $\sigma_{R x}$ was obained by $\varphi=90^{\circ}$ and $270^{\circ}, \sigma_{R y}$ was obtaied 
by $\varphi=0$ and $180^{\circ}$, respectively. Namely, 12 frames in Table 2 were used to obtain $\sigma_{R x}$ and $\sigma_{R y}$, respectively.

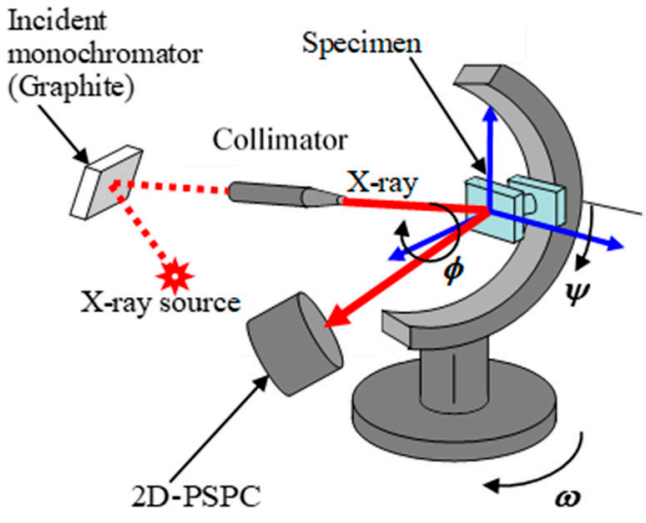

(a)

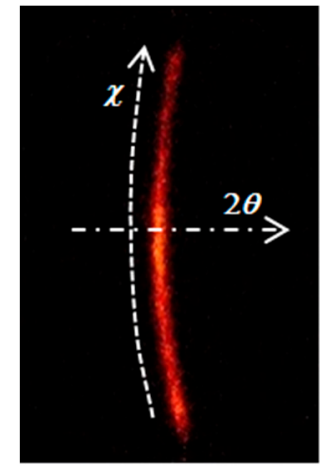

(b)

Figure 5. Schematic diagram and coordinates of XRD system with 2D-PSPC. (a) Coordinates of the system; (b) coordinates on the 2D-PSPC.

Table 2. Measuring conditions for each method.

\begin{tabular}{ccc}
\hline Method & $\psi^{\circ}$ & $\varphi^{\circ}$ \\
\hline & 0 & $0,90,180,270$ \\
& 20.268 & $0,90,180,270$ \\
$\sin ^{2} \psi$ method & 29.334 & $0,90,180,270$ \\
& 36.870 & $0,90,180,270$ \\
& 43.854 & $0,90,180,270$ \\
2D method & 50.768 & $0,90,180,270$ \\
\hline & 0 & $0,45,90,135,180,225,270,315$ \\
& 30 & $0,45,90,135,180,225,270,315$ \\
& 60 & $0,45,90,135,180,225,270,315$ \\
\hline
\end{tabular}

Table 3. Analyzed area of obtained X-ray diffraction.

\begin{tabular}{ccc}
\hline Method & $\mathbf{2 \boldsymbol { \theta } ^ { \circ }}$ & $\chi^{\circ}$ \\
\hline $\sin ^{2} \psi$ method & $125-132$ & $85-95$ \\
\hline 2D method & $125-132$ & $70-110$ \\
\hline
\end{tabular}

\subsection{Observation of Specimen Surface}

To investigate the grain size of the tested material, the surface was observed using a scanning electron microscope (SEM; JCM-7000, JEOL Ltd., Tokyo, Japan). The aspect of the laser-cavitation-peened specimen was also observed using a laser confocal microscope (VK-100, Keyence Corporation, Osaka, Japan) to obtain the surface profile.

\section{Results}

3.1. Comparison of Measured Residual Stress between the Slitting Method, $\sin ^{2} \psi$ Method and 2D Method

In order to compare the residual stress measured by the slitting method, the $\sin ^{2} \psi$ method and the 2D method, Figure 6 illustrates the residual stress $\sigma_{R y}$ of specimen A. For the $\sin ^{2} \psi$ method and the 2D method, the effect of the measuring area was investigated by changing diameter of the collimator $d_{c o l}$. As shown in Figure 6, the exposure time at each frame $t_{\text {exp }}$ was also changed based on the area of the collimator. In the case of $d_{c o l}=0.8 \mathrm{~mm}$ and $t_{\text {exp }}=20 \mathrm{~s}$, the specimen was moved in both directions, $x= \pm 2 \mathrm{~mm}$ and $y= \pm 2 \mathrm{~mm}$, 
to minimize the exposure time. As shown in Figure 6, in the case of $d_{c o l}=0.8 \mathrm{~mm}$ and $t_{\text {exp }}=40 \mathrm{~s}$ at $x= \pm 0 \mathrm{~mm}$ and $y= \pm 0 \mathrm{~mm}$, the residual stress $\sigma_{R}$ measured using the $\sin ^{2} \psi$ method and the 2D method was $-220 \pm 74$ and $-220 \pm 14 \mathrm{MPa}$; these results are similar to $-251 \pm 16 \mathrm{MPa}$, which was measured by the slitting method. For the $\sin ^{2} \psi$ method, the residual stress measured using $d_{c o l} \geq 0.5724 \mathrm{~mm}$ was similar to that of the slitting method. However, at $d_{c o l} \leq 0.5 \mathrm{~mm}$, the residual stress was too small and the standard deviation of the residual stress was too large. For the reference, Appendix A reveals the diagram of $\sin ^{2} \psi-2 \theta$ for $d_{c o l}=0.146 \mathrm{~mm}, t_{\text {exp }}=20 \mathrm{~min}$ and $d_{c o l}=0.8 \mathrm{~mm}, t_{\text {exp }}=40 \mathrm{~s}$. On the other hand, in the case of the 2D method, the residual stress measured using $d_{c o l}=0.146 \mathrm{~mm}$ was $-187 \pm 29 \mathrm{MPa}$. Thus, it can be concluded that the 2D method can evaluate the residual stress by using $d_{c o l}=0.146 \mathrm{~mm}$. Specifically, the 2D method can measure the residual stress in the $1 / 15$ region of the $\sin ^{2} \psi$ method under the presented conditions.

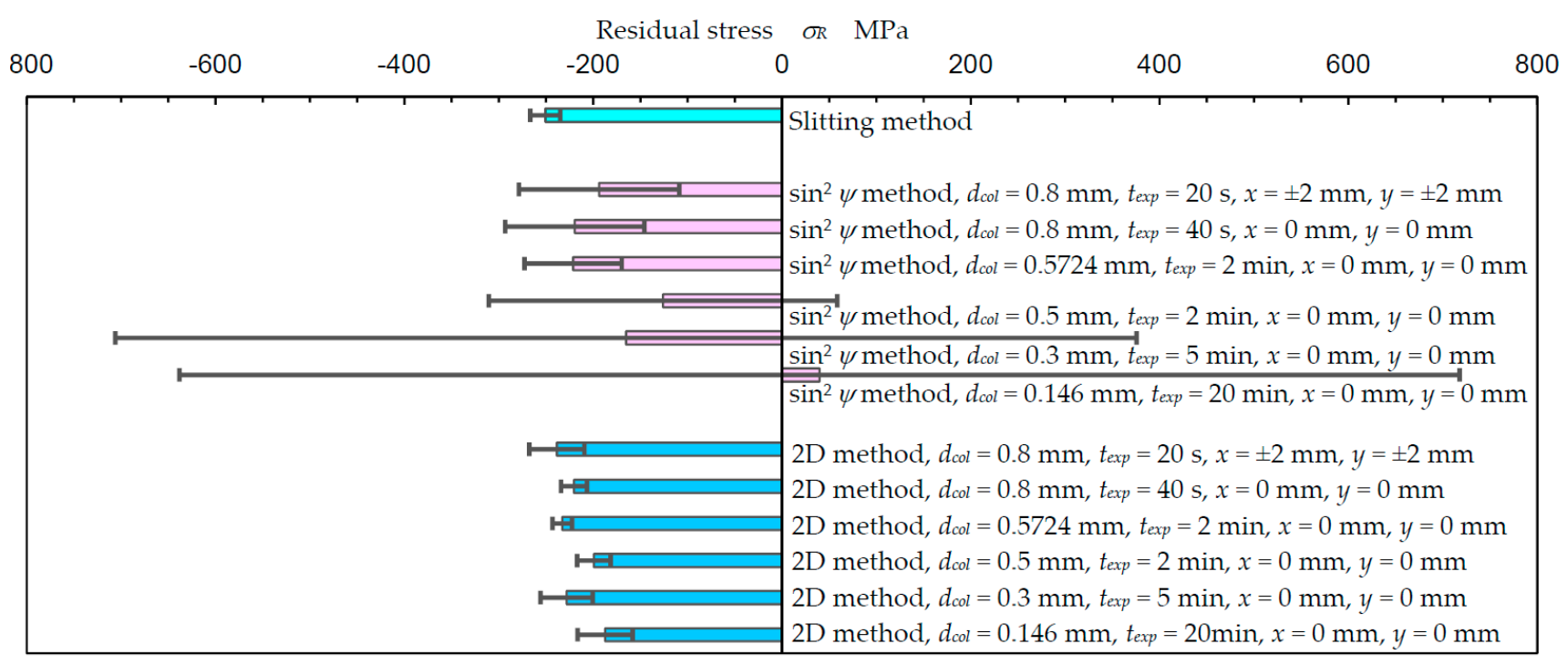

Figure 6. Comparison of the slitting method, $\sin ^{2} \psi$ method, and the $2 \mathrm{D}$ method for the residual stress of stainless steel treated by cavitation peening (specimen $\mathrm{A}$ ).

In order to investigate the difference in the measurement of residual stress between the $\sin ^{2} \psi$ method and the 2D method for the austenitic stainless steel tested using a collimator of $d_{c o l}=0.146 \mathrm{~mm}$, Figure 7 shows the aspects of the surface of the measured sample observed using a scanning electron microscope (SEM). The average grain size, i.e., spatial diameter [46], was $6.6 \pm 4.0 \mu \mathrm{m}$ in diameter, and the grain size that occupied $50 \%$ of the area was about $11 \mu \mathrm{m}$. As shown in Figure 7, specific anisotropy is not observed. Thus, at the present condition, the rolling direction did not affect the results of residual stress measurement.

Figure 8 illustrates a typical X-ray diffraction pattern that was a part of the Debye ring, as detected by 2D-PSPC from the stainless steel treated by cavitation peening-i.e., specimen A treated using $d_{c o l}=0.146 \mathrm{~mm}$ - and the analyzed area for (a) the $\sin ^{2} \psi$ method and (b) the 2D method. As illustrated in Figure 7, the grain size was about $1 / 10$ of the diameter of the collimator, and the X-ray diffraction pattern was a mottled pattern, as shown in Figure 8. In the case of the $\sin ^{2} \psi$ method, the diffraction pattern located near $\chi \approx 90^{\circ}$ should be used due to the theory of the $\sin ^{2} \psi$ method; the standard deviations of the $\sin ^{2} \psi$ method at $d_{c o l} \leq 0.5 \mathrm{~mm}$ were remarkably large, as the diffraction pattern at $\chi \approx 90^{\circ}$ was weak or not obtained. For the present residual stress analysis, $\chi=85-95^{\circ}$ was used for the $\sin ^{2} \psi$ method. The residual stress obtained by the $\sin ^{2} \psi$ method for $d_{c o l}=0.8 \mathrm{~mm}, t_{\text {exp }}=40 \mathrm{~s}, x=0 \mathrm{~mm}$ and $y=0 \mathrm{~mm}$ was $-300 \pm 46 \mathrm{MPa}$ based on analysis using $2 \theta=125-132^{\circ}$ and $\chi=70-110^{\circ}$. These values were too large compared to the value of $-251 \pm 16 \mathrm{MPa}$ measured by the slitting method. Namely, when large area, i.e., $\chi=70-110^{\circ}$. was used, the number of counts of the $X$-ray diffraction was increased. However, $\chi=70-110^{\circ}$ was too large for the $\sin ^{2} \psi$ method. 
On the other hand, $\chi=70-110^{\circ}$ was used for the 2D method, as the 2D method obtained the residual stress from the distortion of the Debye ring. For the 2D method, the Debye ring was obtained by interpolation and extrapolation of the patchy patterns of the diffraction spots. It was concluded that the 2D method could evaluate the residual stress in a smaller area compared to the $\sin ^{2} \psi$ method, as the Debye ring was used in the relatively large area of $\chi$. Thus, it can be said that the key point for evaluating the residual stress in a small area is to obtain a more uniform Debye ring.

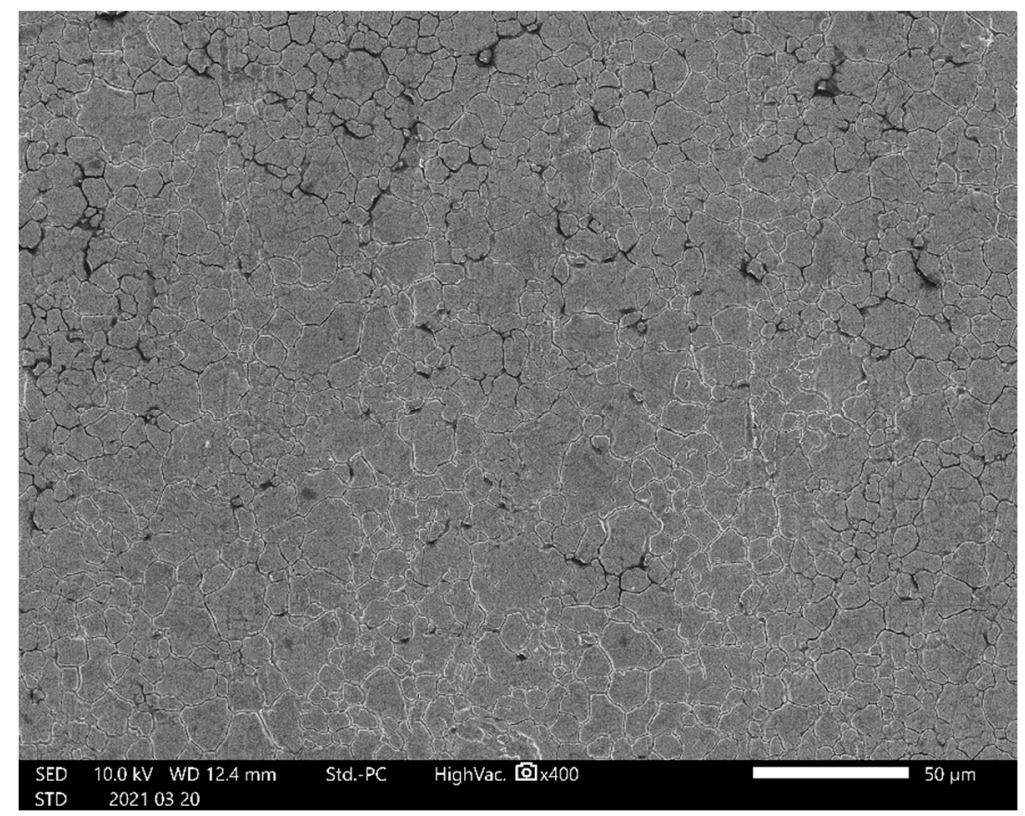

Figure 7. Aspect of the surface of specimen A observed by scanning electron microscope (SEM).

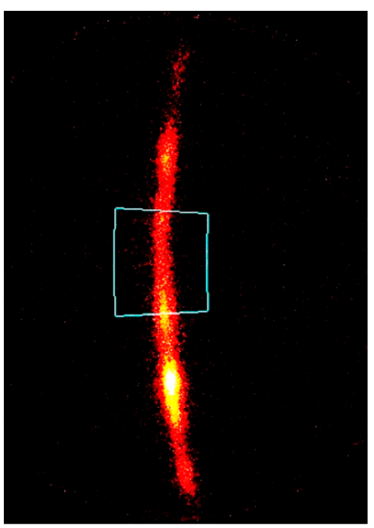

(a)

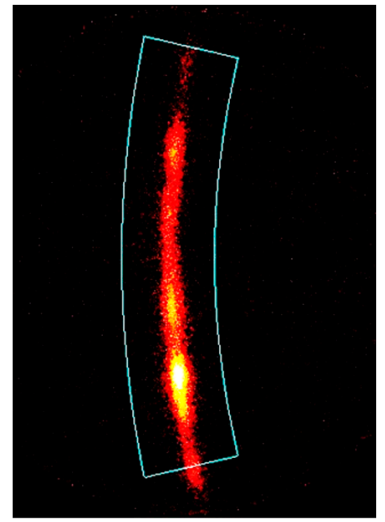

(b)

Figure 8. Typical X-ray diffraction pattern detected by 2D-PSPC from stainless steel treated using cavitation peening (Specimen A) and the analyzed area $\left(d_{c o l}=0.146 \mathrm{~mm}, \psi=0^{\circ}, \varphi=0^{\circ}, \Delta \omega=0^{\circ}\right.$, $\left.t_{\text {exp }}=20 \mathrm{~min}, x=0 \mathrm{~mm}, y=0 \mathrm{~mm}\right) ;\left(\right.$ a) analyzed area for the $\sin ^{2} \psi$ method $\left(2 \theta=125-132^{\circ}, \chi=85-95^{\circ}\right)$; (b) analyzed area for the $2 \mathrm{D}$ method $\left(2 \theta=125-132^{\circ}, \chi=70-110^{\circ}\right)$.

\subsection{Optimum Condition for the 2D Method to Evaluate Residual Stress}

In the present paper, to obtain a better Debye ring, specimen oscillation in the $\omega$ direction-i.e., $\omega$-oscillation-was proposed. Figure 9 shows the X-ray diffraction pattern (a) without $\omega$-oscillation (i.e., $\Delta \omega=0^{\circ}$ ) and (b) with $\omega$-oscillation at $\Delta \omega=10^{\circ}$. As shown in Figure $9 \mathrm{a}(\psi=0, \varphi=0)$ and $(\mathrm{b})(\psi=0, \varphi=0)$, the diffraction spot at $\chi \approx 102^{\circ}$ became a streak by $\omega$-oscillation. Precisely, the diffraction spot became a streak in the $\chi$ direction by $\omega$-oscillation of the specimen. The $\omega$-oscillation helped to achieve a better 
Debye ring. Note that, in the case of 2D method, there should be an optimum value of $\Delta \omega$, as the residual stress was obtained by the distortion of Debye ring. The optimum value of $\Delta \omega$ is discussed in the following.

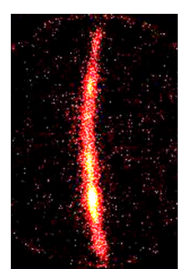

$\psi=0, \varphi=0$

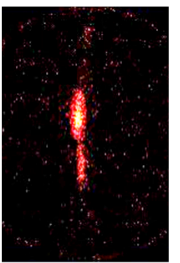

$\psi=30, \varphi=0$

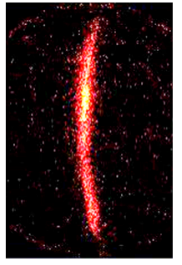

$\psi=60, \varphi=0$

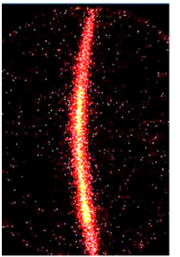

$\psi=0, \varphi=0$

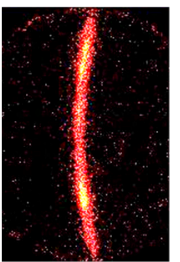

$\psi=30, \varphi=0$

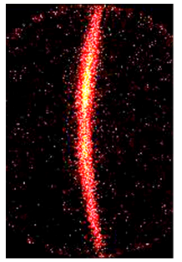

$\psi=60, \varphi=0$

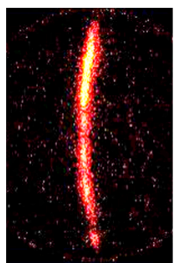

$\psi=0, \varphi=45$

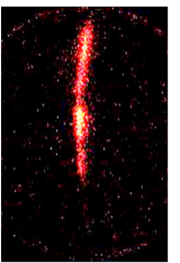

$\psi=30, \varphi=45$

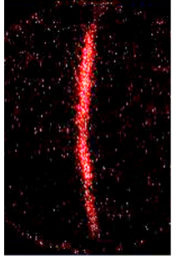

$\psi=60, \varphi=45$

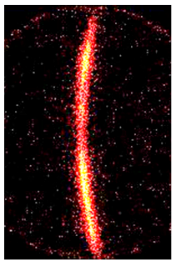

$\psi=0, \varphi=45$

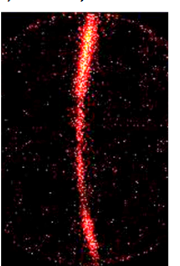

$\psi=30, \varphi=45$

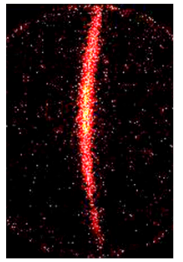

$\psi=60, \varphi=45$

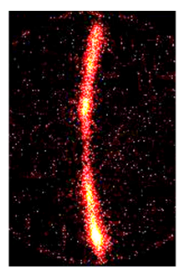

$\psi=0, \varphi=90$

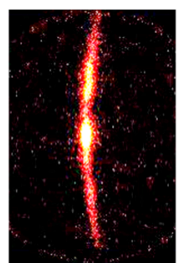

$\psi=30, \varphi=90$

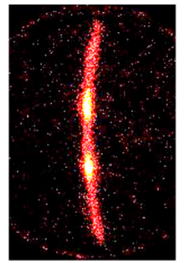

$\psi=60, \varphi=90$

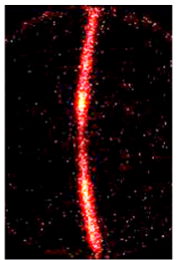

$\psi=0, \varphi=90$

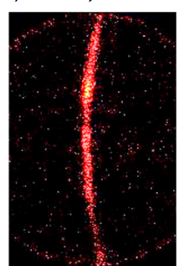

$\psi=30, \varphi=90$

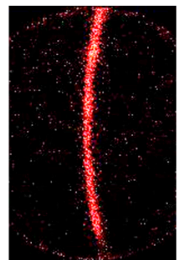

$\psi=60, \varphi=90$

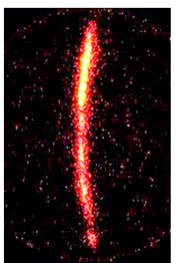

$\psi=0, \varphi=135$

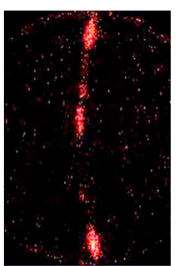

$\psi=30, \varphi=135$

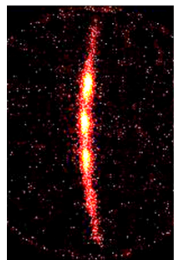

$\psi=60, \varphi=135$

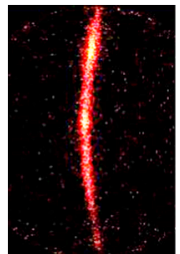

$\psi=0, \varphi=135$

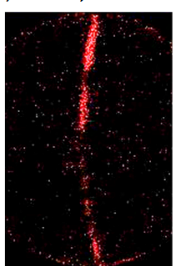

$\psi=30, \varphi=135$

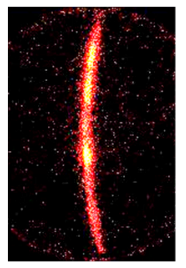

$\psi=60, \varphi=135$
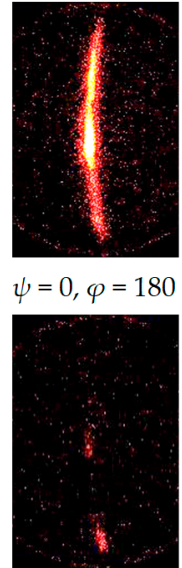

$\psi=30, \varphi=180$

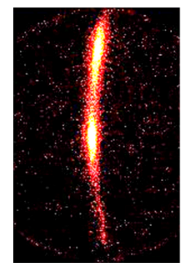

$\psi=60, \varphi=180$

(a)

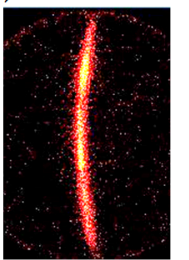

$\psi=0, \varphi=180$

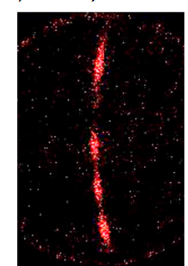

$\psi=30, \varphi=180$

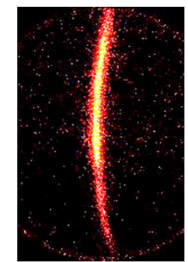

$\psi=60, \varphi=180$

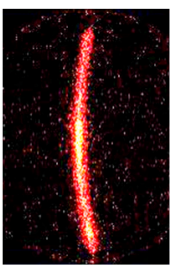

$\psi=0, \varphi=225$

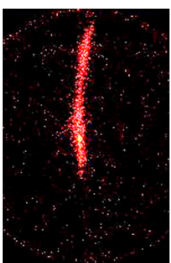

$\psi=30, \varphi=225$

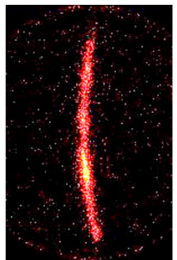

$\psi=60, \varphi=225$

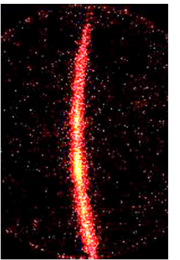

$\psi=0, \varphi=225$

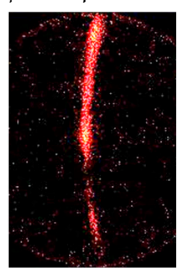

$\psi=30, \varphi=225$

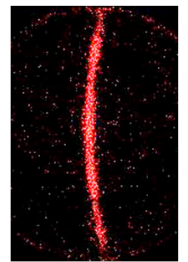

$\psi=60, \varphi=225$

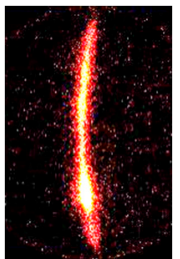

$\psi=0, \varphi=270$

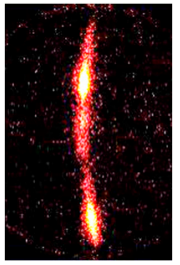

$\psi=30, \varphi=270$

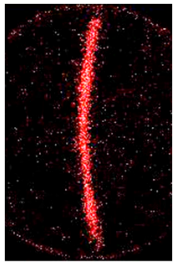

$\psi=60, \varphi=270$

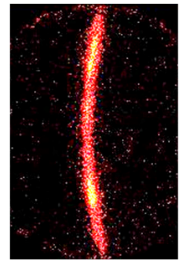

$\psi=0, \varphi=270$

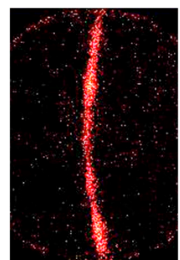

$\psi=30, \varphi=270$

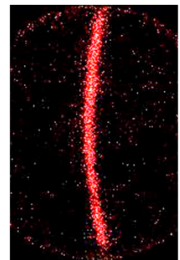

$\psi=60, \varphi=270$

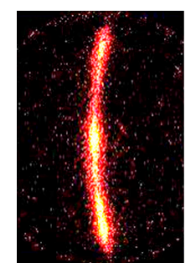

$\psi=0, \varphi=315$

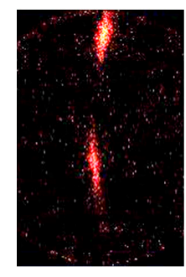

$\psi=30, \varphi=315$

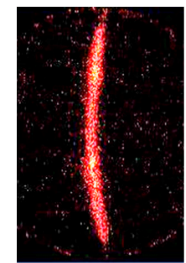

$\psi=60, \varphi=315$

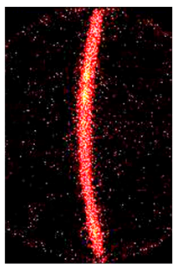

$\psi=0, \varphi=315$

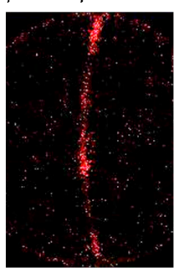

$\psi=30, \varphi=315$

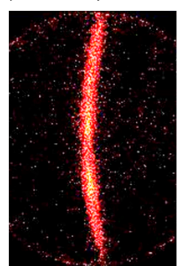

$\psi=60, \varphi=315$

(b)

Figure 9. X-ray diffraction patterns detected by 2D-PSPC from the stainless steel treated by cavitation peening (Specimen A). (a) $\Delta \omega=0^{\circ}$; (b) $\Delta \omega=10^{\circ}$.

In order to investigate the $\omega$-oscillation of the specimen both qualitatively and quantitatively, Figure 10 shows the typical X-ray diffraction pattern of specimen $\mathrm{A}$ at $\psi=0^{\circ}$ 
and $\varphi=0$ changing with (a) the collimator diameter $d_{c o l}$, (b) the exposure time $t_{\exp }$ and (c) the $\omega$-oscillation angle $\Delta \omega$. Figure 11 illustrates the relationship between the total count of X-ray diffraction and the standard deviation of the residual stress $\Delta \sigma_{R}$. As shown in Figure 10a, the $\mathrm{X}$-ray diffraction pattern became a mottled pattern with a decrease in the diameter of the collimator $d_{c o l}$. Then, the $\Delta \sigma_{R}$ increased with a decrease of $d_{c o l}$, as shown in Figure 11. When the exposure time $t_{\exp }$ was increased, the Debye ring became clear, as shown in Figure $10 \mathrm{~b}$, and then $\Delta \sigma_{R}$ decreased with an increase of $t_{\text {exp }}$. As shown in Figure 11, $\Delta \sigma_{R}$ decreased with an increase in the total count of X-ray diffraction for both $d_{c o l}$ and $t_{\text {exp }}$. As shown in Figure 10c, the diffraction pattern changed from a mottled pattern to a streak-like pattern with an increase of $\Delta \omega$. The $\Delta \sigma_{R}$ was $64 \mathrm{MPa}$ for $\Delta \omega=0^{\circ}$, $49 \mathrm{MPa}$ for $\Delta \omega=2^{\circ}, 49 \mathrm{MPa}$ for $\Delta \omega=4^{\circ}, 37 \mathrm{MPa}$ for $\Delta \omega=6^{\circ}, 29 \mathrm{MPa}$ for $\Delta \omega=8^{\circ}$ and $32 \mathrm{MPa}$ for $\Delta \omega=10^{\circ}$. Specifically, $\Delta \sigma_{R}$ decreased with an increase of $\Delta \omega$ at $\Delta \omega=0-8^{\circ}$ and presented its minimum at $\Delta \omega=8^{\circ}$; then, $\Delta \sigma_{R}$ slightly increased at $\Delta \omega=10^{\circ}$. As the $2 \mathrm{D}$ method evaluates the residual stress caused by distortion of the Debye ring, a $\Delta \omega$ that is too large dims the distortion by averaging too large an area in the $\chi$ direction. Thus, it can be concluded that the $\omega$-oscillation of the specimen was effective, and the optimum value of $\Delta \omega$ was $8^{\circ}$. In Figure 11, $\Delta \sigma_{R}=64 \mathrm{MPa}$. In Figure 11, $\Delta \sigma_{R}=64 \mathrm{MPa}$ for $\Delta \omega=0^{\circ}$ corresponds to $t_{\exp }=4$ or $5 \mathrm{~min}$ and $\Delta \sigma_{R}=29 \mathrm{MPa}$ for $\Delta \omega=8^{\circ}$ corresponds to $t_{\exp }=20 \mathrm{~min}$. Thus, $\omega$-oscillation of the specimen has the effect of shortening the measurement time to $1 / 4-1 / 5$.
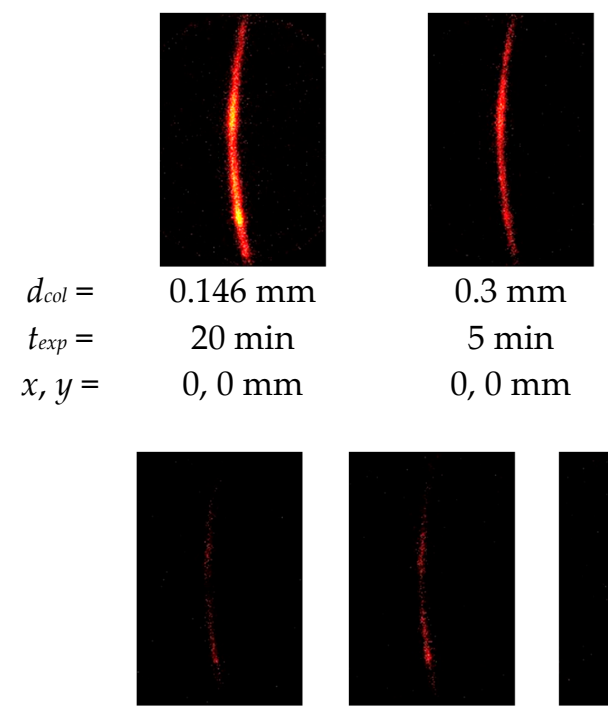

$2 \min$

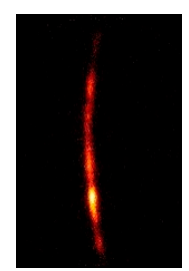

$0^{\circ}$

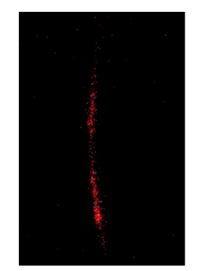

$3 \mathrm{~min}$

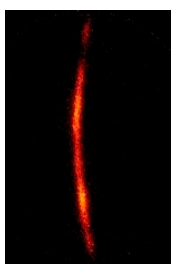

$2^{\circ}$

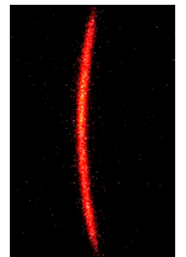

$0.5 \mathrm{~mm}$ $2 \mathrm{~min}$

0, $0 \mathrm{~mm}$

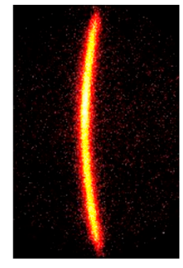

$0.5724 \mathrm{~mm}$ 2 min

0, $0 \mathrm{~mm}$

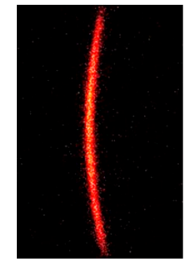

$0.8 \mathrm{~mm}$ $40 \mathrm{~s}$

0, $0 \mathrm{~mm}$

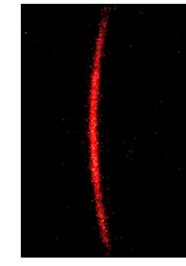

$0.8 \mathrm{~mm}$ $20 \mathrm{~s}$ $\pm 2, \pm 2 \mathrm{~mm}$

(a)

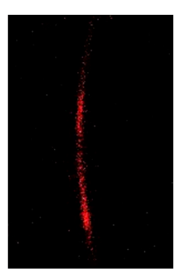

4 min

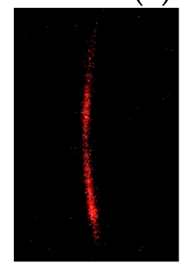

5 min

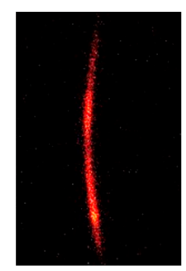

10 min

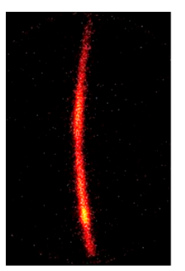

15 min

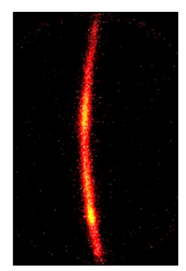

20 min

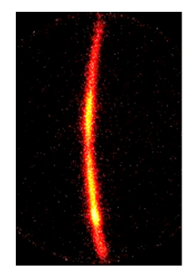

$30 \mathrm{~min}$

(b)

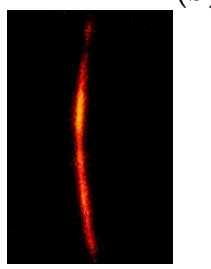

$4^{\circ}$

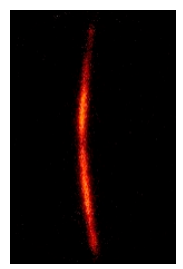

$6^{\circ}$

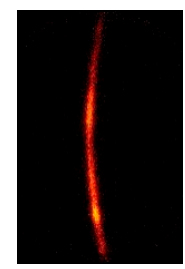

$8^{\circ}$

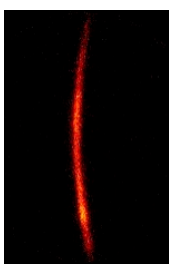

$10^{\circ}$

(c)

Figure 10. Typical X-ray diffraction patterns detected by 2D-PSPC at $\psi=0^{\circ}$ and $\varphi=0^{\circ}$ from stainless steel treated by cavitation peening (Specimen A). (a) effect of the collimator diameter $d_{c o l}$ at $\Delta \omega=8^{\circ}$; (b) effect of exposure time $t_{\text {exp }}$ at $d_{c o l}=0.146 \mathrm{~mm}$ and $\Delta \omega=8^{\circ} ;(\mathbf{c})$ effect of the $\omega$-oscillation angle $\Delta \omega$ at $d_{c o l}=0.146 \mathrm{~mm}$ and $t_{\text {exp }}=20 \mathrm{~min}$.

In order to confirm that the 2D method can evaluate the residual stress of the austenitic stainless steel by using the $0.146 \mathrm{~mm}$-diameter collimator, Figure 12a reveals the residual stress $\left(\sigma_{R x}, \sigma_{R y}\right)$ of specimen $\mathrm{A}, \mathrm{B}$ and $\mathrm{C}$ as a function of the diameter of the collimator $d_{c o l}$, 
and Figure $12 \mathrm{~b}$ shows the standard deviation of the residual stress. The data for specimen A in Figure 6 were used as the $\sigma_{R y}$ in Figure 12. For all three specimens, A, B and C, as both $\sigma_{R x}$ and $\sigma_{R y}$ at $d_{c o l}=0.146 \mathrm{~mm}$ were nearly equal to the values at $d_{c o l}=0.8 \mathrm{~mm}$, the residual stresses of $d_{c o l}=0.146 \mathrm{~mm}$ for specimens $\mathrm{A}, \mathrm{B}$ and C were able to be evaluated.

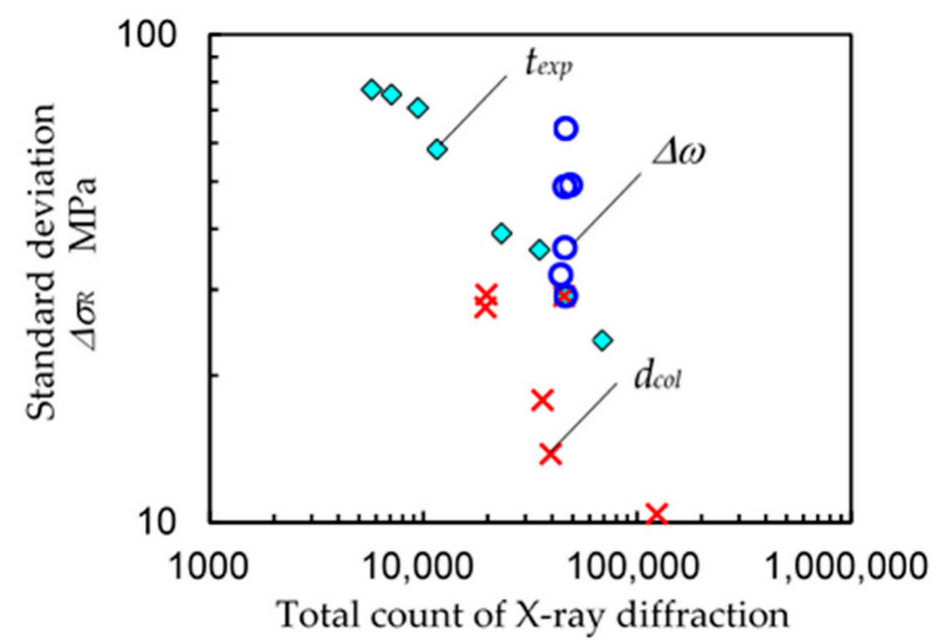

Figure 11. Relationship between the counts at $\psi=0^{\circ}$ and $\varphi=0^{\circ}$ detected by 2D-PSPC and the standard deviation of the residual stress of stainless steel treated by cavitation peening (specimen A) changing with exposure time $t_{\text {exp }}$, collimator diameter $d_{c o l}$ and $\omega$-oscillation angle $\Delta \omega$.

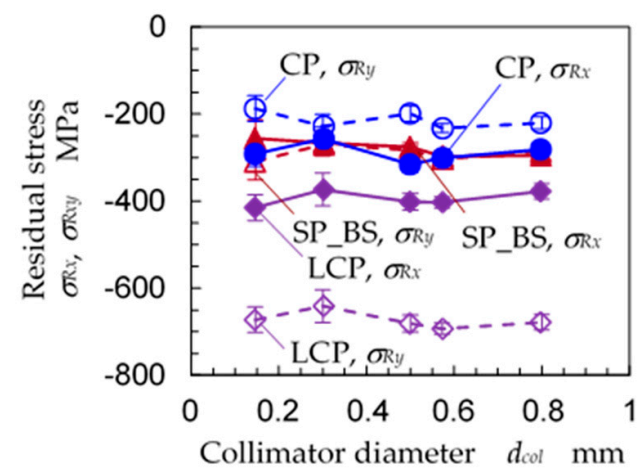

(a)

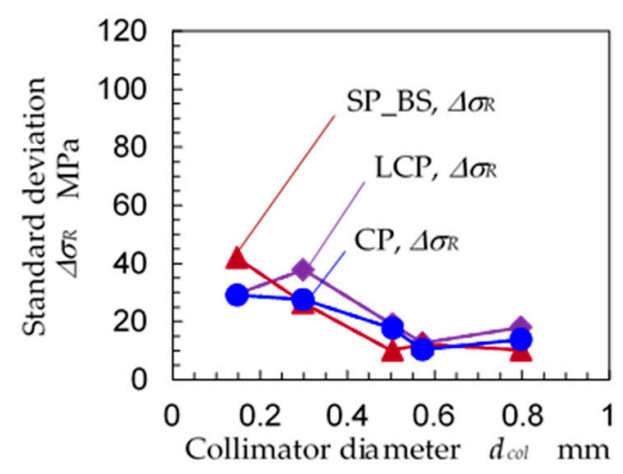

(b)

Figure 12. Effect of the collimator dimeter on the residual stress measurement of the stainless steel by the 2D method $\left(\Delta \omega=8^{\circ}\right)$; CP: specimen A, LCP: specimen B, SP_BS: specimen C. (a) residual stress; (b) standard deviation of residual stress.

In the case of specimen B, i.e., $\mathrm{LCP}$, the specimen was treated with $100 \mathrm{pulses} / \mathrm{mm}^{2}$, as mentioned in Table 1 . The specimen was moved in the $x$-direction at $1 \mathrm{~mm} / \mathrm{s}$. As the repetition frequency of the pulse laser was $10 \mathrm{~Hz}$, the distance of each laser spot was $0.1 \mathrm{~mm}$. After each specimen was treated in the $x$-direction, it was moved stepwise at $0.1 \mathrm{~mm}$ in the $y$-direction. As shown in Figure $12 \mathrm{a}, \sigma_{R x}$ and $\sigma_{R y}$ were about $-400 \mathrm{MPa}$ and $-670 \mathrm{MPa}$, respectively. Specifically, the compressive residual stress introduced in $y$-direction, i.e., the stepwise direction, under laser cavitation peening was $270 \mathrm{MPa}$ larger than that in the $x$-direction. Even though the distances between the laser spots in both $x$ and $y$-direction were the same, the compressive residual stress introduced in the $y$-direction was larger than that in the $x$-direction. This tendency was similar to the results in the reference [38].

In the present experiment, SP was applied, then the residual stress on the back side of shot peened specimen was measured to avoid the effects of the change of the grain size etc. 
If the treated surfaces by SP, CP and LCP were evaluated, the characteristics of the peened surfaces have different features. It was reported that the dislocation density of CP and LCP of austenitic stainless steel SUS316L was lower than that of SP at the equivalent peening condition, i.e., the equivalent arc height condition [48].

In order to investigate the effects of $\omega$-oscillation of the specimen, Figure 13 reveals the residual stress $\left(\sigma_{R x}, \sigma_{R y}\right)$ and the standard deviation of the residual stress $\Delta \sigma_{R}$ as a function of the $\omega$-oscillation angle $\Delta \omega$ for specimens A, B and C. As shown in Figure 13, the residual stress of specimen $\mathrm{A}, \mathrm{B}$ and $\mathrm{C}$ was roughly constant for all $\Delta \omega$ values, and $\Delta \sigma_{R}$ roughly decreased with an increase of $\Delta \omega$. In the case of LCP, i.e., specimen $C$, the compressive residual stress increased with an increase of $\Delta \omega$ at $\Delta \omega \leq 8^{\circ}$; then, the compressive residual stress slightly decreased at $\Delta \omega=10^{\circ}$. Further, the $\Delta \sigma_{R}$ of specimen $C$ had its minimum at $\Delta \omega=8^{\circ}$, and the $\Delta \sigma_{R}$ at $\Delta \omega=10^{\circ}$ was larger than the $\Delta \sigma_{R}$ of $\Delta \omega=8^{\circ}$. As the 2D method obtained the residual stress from the distortion of the Debye ring, a $\Delta \omega$ value that was too large caused a decrease of the residual stress and an increase of $\Delta \sigma_{R}$, just as with specimen A. It can be concluded that the $\omega$-oscillation of the specimen is effective for evaluating the residual stress and that the optimum value of $\Delta \omega$ is $8^{\circ}$.

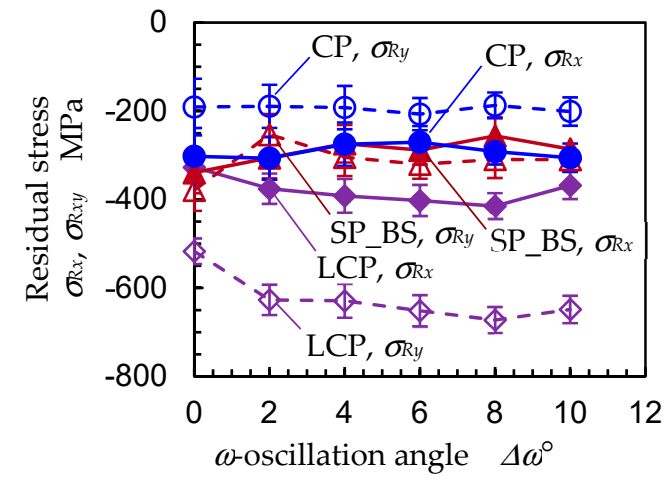

(a)

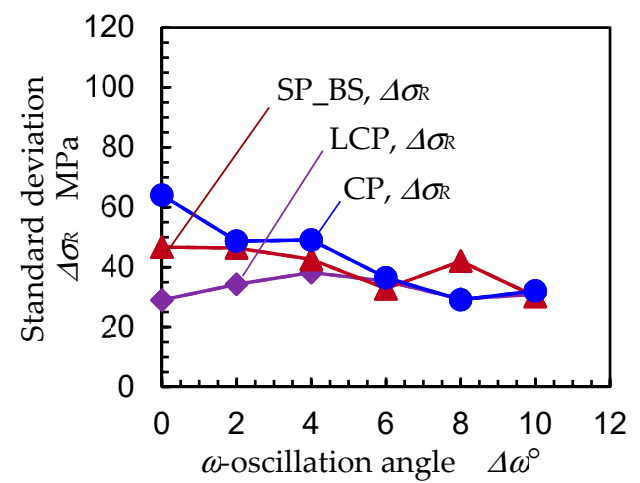

(b)

Figure 13. Effect of the $\omega$-oscillation angle $\Delta \omega$ on the residual stress measurement of stainless steel using the 2D method ( $\left.d_{c o l}=0.146 \mathrm{~mm}, t_{\text {exp }}=20 \mathrm{~min}\right)$; CP: specimen A, LCP: specimen B, SP_BS: specimen $C$; (a) residual stress; (b) standard deviation of residual stress.

In order to determine the optimum exposure time needed to obtain the X-ray diffraction pattern, Figure 14 shows (a) the residual stress $\sigma_{R x}, \sigma_{R y}$ and (b) standard deviation of the residual stress $\Delta \sigma_{R}$ as a function of exposure time $t_{\exp }$ for specimens $\mathrm{A}, \mathrm{B}$ and $\mathrm{C}$. Under all measurement conditions in Figure 14, the specimens were oscillated at $\Delta \omega=8^{\circ}$, and the diameter of the collimator was $0.146 \mathrm{~mm}$. For specimens $\mathrm{A}$ and $\mathrm{B}$, the $\sigma_{R x}$ and $\sigma_{R y}$ were nearly constant at all $t_{\exp }$ values. For specimen $\mathrm{C}, \sigma_{R x}$ and $\sigma_{R y}$ decreased and became saturated at $t_{\text {exp }}=15$ and $20 \mathrm{~min}$. The $\Delta \sigma_{R}$ of specimens $\mathrm{A}, \mathrm{B}$ and $\mathrm{C}$ decreased with an increase of $t_{\text {exp }}$ and became saturated at $t_{\exp }=15$ or $20 \mathrm{~min}$. Under the studied conditions, $t_{\text {exp }}=20 \mathrm{~min}$ is the optimum exposure time to obtain residual stress. The X-ray diffraction totaled about $4.6 \times 10^{4}$ counts. 


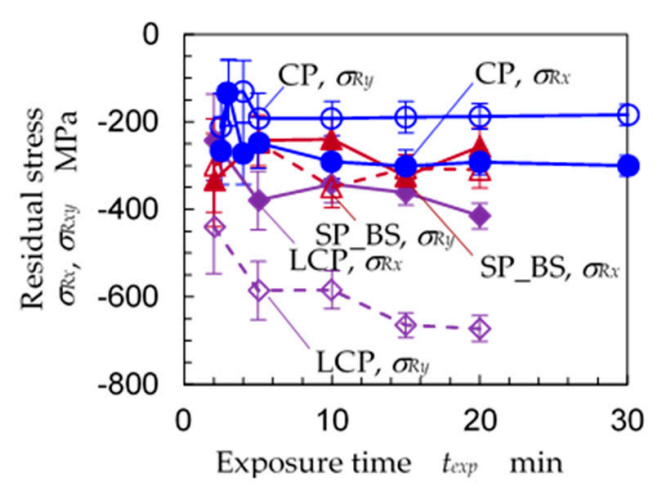

(a)

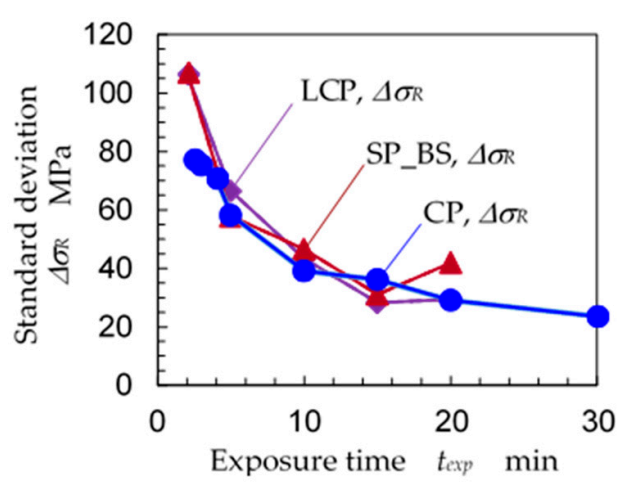

(b)

Figure 14. Effect of exposure time $t_{\exp }$ on the residual stress measurements of stainless steel under the 2D method $\left(d_{c o l}=0.146 \mathrm{~mm}, \Delta \omega=8^{\circ}\right)$; CP: specimen A, LCP: specimen B, SP_BS: specimen C. (a) Residual stress; (b) standard deviation of residual stress.

\subsection{Residual Stress Distribution of Specimen Treated by Laser Cavitation Peening}

To determine the typical results for the residual stress of austenitic stainless steel JIS SUS316L in the local area measured by the 2D method, the residual stress of the specimen treated by laser cavitation peening, i.e., that of specimen D, was evaluated using the 2D method. Considering the results in Sections 3.1 and 3.2, the measuring conditions were as follows: The diameter of the collimator $d_{\text {col }}$ was $0.146 \mathrm{~mm}$, the $\omega$-oscillation angle $\Delta \omega$ was $8^{\circ}$ and the exposure time of each frame $t_{\text {exp }}$ was $20 \mathrm{~min}$. The pulse density of the laser cavitation peening $d_{L}$ was 4 pulses $/ \mathrm{mm}^{2}$, as the fatigue life was greatest at $d_{L}=4$ pulses $/ \mathrm{mm}^{2}$ and changed with the pulse density [23]. Under these conditions, the laser spot distances in the $x$ - and $y$-directions were 0.5 and $0.5 \mathrm{~mm}$, respectively. As mentioned above, the top surface revealed tensile residual stress, and then the surface of $33 \mu \mathrm{m}$ was removed by electrochemical polishing. Note that the residual stress at $30 \mu \mathrm{m}$ accurately corresponded to the fatigue life, as the fatigue life estimated by the residual stress at $30 \mu \mathrm{m}$, the surface hardness and the surface roughness was proportional to the experimental value [23].

Figure 15 shows (a) the aspects of the laser-cavitation-peened specimen observed using a CCD camera on the XRD system and (b) the aspects of the same specimen observed using a laser confocal microscope. As the specimen was treated with $d_{L}=4$ pulses $/ \mathrm{mm}^{2}$, the distances of the $x$ - and $y$-directions between the laser spots were 0.5 and $0.5 \mathrm{~mm}$. Under the presented conditions, the depth of the laser spot was about $10 \mu \mathrm{m}$. As shown in Figure 15, the laser spot diameter was about $0.5 \mathrm{~mm}$ after the $33 \mu \mathrm{m}$ electrochemical polishing. The vertical positional relationship of the laser spots was not aligned, as the stepping motor and laser system were not synchronized.

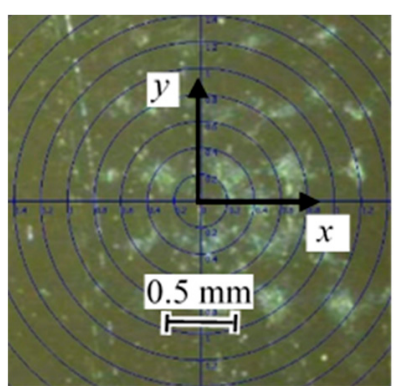

(a)

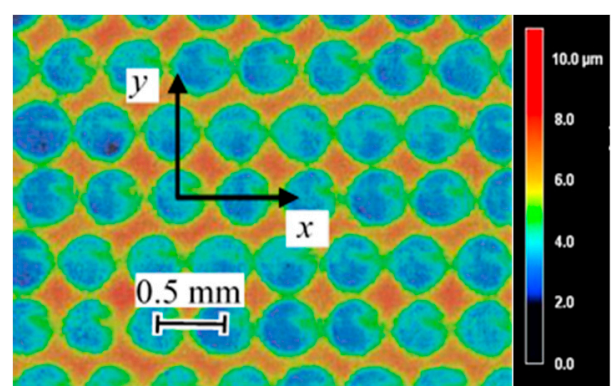

(b)

Figure 15. Aspects of the surface of the stainless-steel specimen treated by laser cavitation peening (specimen D); (a) observation using the CCD camera on the XRD system; (b) observations from the laser confocal microscope. 
Figure 16 shows the residual stress distribution as a function of $y$ at $x=0,0.125,0.25$, 0.375 and $0.5 \mathrm{~mm}$ for (a) $\sigma_{R x}$ and (b) $\sigma_{R y}$. The standard deviation at the residual stress was about $70 \mathrm{MPa}$. It was difficult to recognize the $0.5 \mathrm{~mm}$ interval period at each position of $x$, as shown in Figure 16a,b, because the positional relationships of the laser spots at $y=0,0.5,1,1.5$ and $2 \mathrm{~mm}$ were different, as shown in Figure 15. As $\sigma_{R x}$ and $\sigma_{R y}$ varied from 0 to $-150 \mathrm{MPa}$, there was a difference of about $150 \mathrm{MPa}$ depending on the location for both $\sigma_{R x}$ and $\sigma_{R y}$.

Figure 17 reveals the residual stress $\sigma_{R x}$ and $\sigma_{R y}$ changing with distance $x$ at $y=0$ with the laser spot aligned in the $x$-direction. The $\sigma_{R x}$ was about $-100 \mathrm{MPa}$ at $x=0 \mathrm{~mm}$; it had a peak of $0 \mathrm{MPa}$ at $x=0.125 \mathrm{~mm}$ and then decreased with an increase in $x$. Then, $\sigma_{R x}$ had a minimum of $150 \mathrm{MPa}$ at $x=0.375 \mathrm{~mm}$ and increased to $0 \mathrm{MPa}$ at $\mathrm{x}=0.5 \mathrm{~mm}$. On the other hand, $\sigma_{R y}$ had a minimum at $\mathrm{x}=0.125 \mathrm{~mm}$ and a maximum at $\mathrm{x}=0.375 \mathrm{~mm}$. Even though the standard deviations were somewhat large, a $0.5 \mathrm{~mm}$ cycle was observed for both $\sigma_{R x}$ and $\sigma_{R y}$. It can be concluded from Figures 16 and 17 that the residual stress may differ by about $150 \mathrm{MPa}$ depending on the location when austenitic stainless steel JIS SUS316L is treated using laser cavitation peening at 4 pulses $/ \mathrm{mm}^{2}$. As shown in Figures 12 and 13, when the residual stress was relatively uniform, the experimental deviation at the present condition using the $0.146 \mathrm{~mm}$ collimator was about $\pm 40 \mathrm{MPa}$. At the measurement of $\mathrm{LCP}$ specimen treated at 4 pulse $/ \mathrm{mm}^{2}$, the residual stress was changed from $0 \mathrm{MPa}$ to $-150 \mathrm{MPa}$ within $0.25 \mathrm{~mm}$ in length, thus the experimental deviation using the $0.146 \mathrm{~mm}$ collimator was about $\pm 70 \mathrm{MPa}$ due to the spatial distribution.

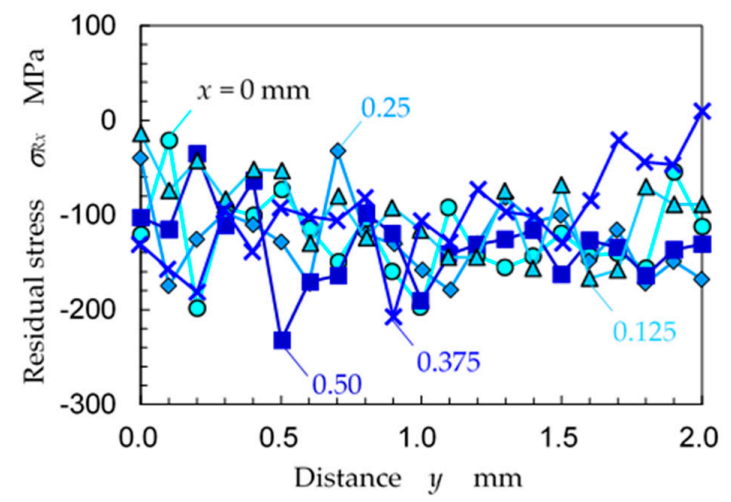

(a)

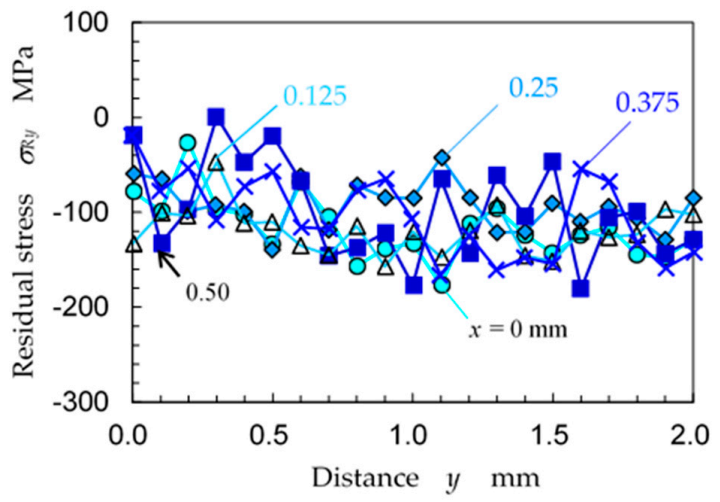

(b)

Figure 16. Distribution of the residual stress changing with distance $y$ at various positions of $x$ (specimen D); (a) residual stress in the $x$-direction $\sigma_{R x} ;(\mathbf{b})$ residual stress in the $y$-direction $\sigma_{R y}$.

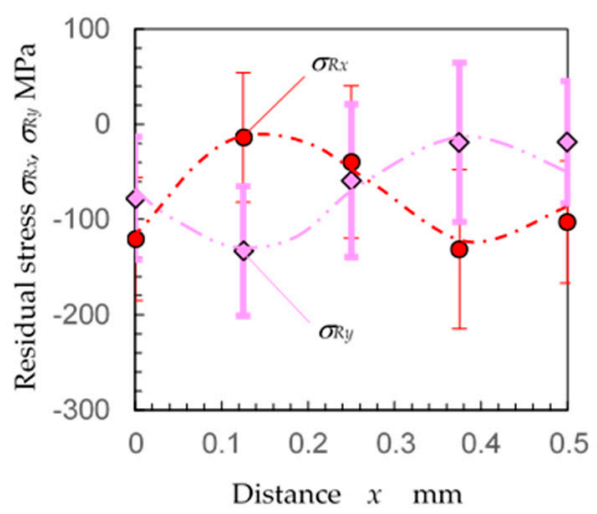

Figure 17. Distribution of the residual stress $\sigma_{R x}$ and $\sigma_{R y}$ changing with distance $x$ (specimen D).

\section{Conclusions}

To clarify the possibilities and measure the conditions of residual stress in a mechanicalsurface-modified layer with a small area by the 2D method using X-ray diffraction, the 
residual stress of the austenitic stainless steel JIS SUS316L treated by cavitation peening was measured by the 2D method changing with the diameter of the collimator comparing with the $\sin ^{2} \psi$ method and the slitting method. The measured sample was austenitic stainless steel with temper rolling. The average diameter and $50 \%$ area of the grain size of the tested specimen were $6.6 \pm 4.0 \mu \mathrm{m}$ and about $11 \mu \mathrm{m}$, respectively. The specimens were treated by cavitation peening using a cavitating jet and a pulse laser, i.e., laser cavitation peening. The results obtained can be summarized as follows:

(1) Compared to the $\sin ^{2} \psi$ method, the $2 \mathrm{D}$ method can evaluate the residual stress in a small area, which is $1 / 15$ of the area ratio of the $\sin ^{2} \psi$ method. In the present experiment, the measurable areas of the $\sin ^{2} \psi$ method and 2D method were $0.5724 \mathrm{~mm}$ in diameter and $0.146 \mathrm{~mm}$ in diameter, respectively.

(2) The $\omega$-oscillation of the specimen using the $2 \mathrm{D}$ method had the effect of reducing the measurement error to $1 / 2$. This result is equivalent to the effect of reducing the measurement time to $1 / 5-1 / 4$. The optimum $\omega$-oscillation angle $\Delta \omega$ was $8^{\circ}$.

(3) The 2D method using optimized conditions can evaluate the residual stress distribution for a laser spot with a diameter of $0.5 \mathrm{~mm}$.

(4) The compressive residual stress under laser cavitation peening at 100 pulses $/ \mathrm{mm}^{2}$ was larger in the stepwise direction than in the orthogonal direction.

Author Contributions: Conceptualization, H.S., C.K. and T.K.; methodology, H.S., C.K. and M.R.H.; validation, H.S. and C.R.C.; formal analysis, H.S. and C.R.C.; investigation, H.S. and C.R.C.; resources, H.S.; data curation, H.S. and C.R.C.; writing-original draft preparation, H.S.; writing-review and editing, H.S. and C.K.; funding acquisition, H.S.; supervision, T.K. and M.R.H. All authors have read and agreed to the published version of the manuscript.

Funding: This research was partly supported by JSPS KAKENHI Grant Number 18KK0103 and 20H02021.

Institutional Review Board Statement: Not applicable.

Informed Consent Statement: Not applicable.

Data Availability Statement: The data presented in this study are available on request from the author.

Conflicts of Interest: The authors declare no conflict of interest.

\section{Appendix A}

For the reference, Figure A1 shows the diagram of $\sin ^{2} \psi-2 \theta$ for $d_{c o l}=0.146 \mathrm{~mm}$, $t_{\text {exp }}=20 \mathrm{~min}$ and $d_{c o l}=0.8 \mathrm{~mm}, t_{\exp }=40 \mathrm{~s}$. As shown in Figure A1, the peak of the profile of the X-ray diffraction, i.e., the diffraction angle of $d_{c o l}=0.146 \mathrm{~mm}$ was scattered, therefore the experimental deviation in Figure 6 of $d_{c o l}=0.146 \mathrm{~mm}$ was large.

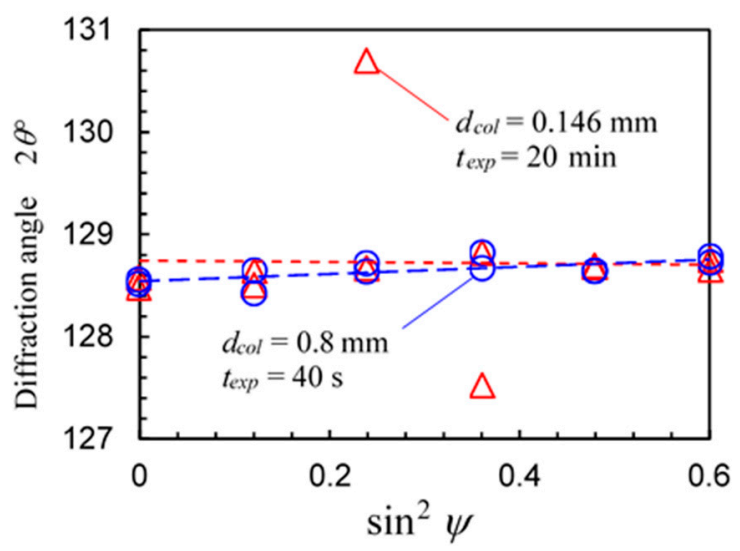

Figure A1. Relationship between $\sin ^{2} \psi-2 \theta\left(d_{c o l}=0.146 \mathrm{~mm}, t_{\text {exp }}=20 \mathrm{~min}\right.$ and $\left.d_{c o l}=0.8 \mathrm{~mm}, t_{\text {exp }}=40 \mathrm{~s}\right)$. 


\section{References}

1. Nikitin, I.; Scholtes, B.; Maier, H.J.; Altenberger, I. High temperature fatigue behavior and residual stress stability of laser-shock peened and deep rolled austenitic steel aisi 304. Scr. Mater. 2004, 50, 1345-1350. [CrossRef]

2. Withers, P.J. Residual stress and its role in failure. Rep. Prog. Phys. 2007, 70, 2211-2264. [CrossRef]

3. Gujba, A.K.; Medraj, M. Laser peening process and its impact on materials properties in comparison with shot peening and ultrasonic impact peening. Materials 2014, 7, 7925-7974. [CrossRef] [PubMed]

4. Soyama, H. Comparison between shot peening, cavitation peening and laser peening by observation of crack initiation and crack growth in stainless steel. Metals 2020, 10, 63. [CrossRef]

5. Arakawa, J.; Hanaki, T.; Hayashi, Y.; Akebono, H.; Sugeta, A. Evaluating the fatigue limit of metals having surface compressive residual stress and exhibiting shakedown. Fatigue Fract. Eng. Mater. Struct. 2020, 43, 211-220. [CrossRef]

6. Bikdeloo, R.; Farrahi, G.H.; Mehmanparast, A.; Mahdavi, S.M. Multiple laser shock peening effects on residual stress distribution and fatigue crack growth behaviour of 316L stainless steel. Theor. Appl. Fract. Mech. 2020, 105, 11. [CrossRef]

7. Tang, L.Q.; Ince, A.; Zheng, J. Numerical modeling of residual stresses and fatigue damage assessment of ultrasonic impact treated 304L stainless steel welded joints. Eng. Fail. Anal. 2020, 108, 23. [CrossRef]

8. Soyama, H.; Chighizola, C.R.; Hill, M.R. Effect of compressive residual stress introduced by cavitation peening and shot peening on the improvement of fatigue strength of stainless steel. J. Mater. Process. Technol. 2021, 288, 116877. [CrossRef]

9. Edwards, L.; Bouchard, P.J.; Dutta, M.; Wang, D.Q.; Santisteban, J.R.; Hiller, S.; Fitzpatrick, M.E. Direct measurement of the residual stresses near a 'boat-shaped' repair in a $20 \mathrm{~mm}$ thick stainless steel tube butt weld. Int. J. Press. Vessels Pip. 2005, 82, 288-298. [CrossRef]

10. Zhang, W.Y.; Jiang, W.C.; Zhao, X.; Tu, S.T. Fatigue life of a dissimilar welded joint considering the weld residual stress: Experimental and finite element simulation. Int. J. Fatigue 2018, 109, 182-190. [CrossRef]

11. Luo, Y.; Gu, W.B.; Peng, W.; Jin, Q.; Qin, Q.L.; Yi, C.M. A study on microstructure, residual stresses and stress corrosion cracking of repair welding on 304 stainless steel: Part i-effects of heat input. Materials 2020, 13, 2416. [CrossRef]

12. Soyama, H. Laser cavitation peening and its application for improving the fatigue strength of welded parts. Metals 2021, 11, 531. [CrossRef]

13. Webster, P.J.; Oosterkamp, L.D.; Browne, P.A.; Hughes, D.J.; Kang, W.P.; Withers, P.J.; Vaughan, G.B.M. Synchrotron X-ray residual strain scanning of a friction stir weld. J. Strain Anal. Eng. Des. 2001, 36, 61-70. [CrossRef]

14. Peel, M.; Steuwer, A.; Preuss, M.; Withers, P.J. Microstructure, mechanical properties and residual stresses as a function of welding speed in aluminium AA5083 friction stir welds. Acta Mater. 2003, 51, 4791-4801. [CrossRef]

15. Prime, M.B.; Gnaupel-Herold, T.; Baumann, J.A.; Lederich, R.J.; Bowden, D.M.; Sebring, R.J. Residual stress measurements in a thick, dissimilar aluminum alloy friction stir weld. Acta Mater. 2006, 54, 4013-4021. [CrossRef]

16. Haghshenas, M.; Gharghouri, M.A.; Bhakhri, V.; Klassen, R.J.; Gerlich, A.P. Assessing residual stresses in friction stir welding: Neutron diffraction and nanoindentation methods. Int. J. Adv. Manuf. Technol. 2017, 93, 3733-3747. [CrossRef]

17. Zhang, L.; Zhong, H.L.; Li, S.C.; Zhao, H.J.; Chen, J.Q.; Qi, L. Microstructure, mechanical properties and fatigue crack growth behavior of friction stir welded joint of 6061-T6 aluminum alloy. Int. J. Fatigue 2020, 135, 11. [CrossRef]

18. Soyama, H.; Simoncini, M.; Cabibbo, M. Effect of cavitation peening on fatigue properties in friction stir welded aluminum alloy AA5754. Metals 2021, 11, 59. [CrossRef]

19. Delosrios, E.R.; Walley, A.; Milan, M.T.; Hammersley, G. Fatigue-crack initiation and propagation on shot-peened surfaces in A316 stainless-steel. Int. J. Fatigue 1995, 17, 493-499. [CrossRef]

20. Peyre, P.; Fabbro, R.; Merrien, P.; Lieurade, H.P. Laser shock processing of aluminium alloys. Application to high cycle fatigue behaviour. Mater. Sci. Eng. A 1996, 210, 102-113. [CrossRef]

21. Sano, Y.; Obata, M.; Kubo, T.; Mukai, N.; Yoda, M.; Masaki, K.; Ochi, Y. Retardation of crack initiation and growth in austenitic stainless steels by laser peening without protective coating. Mater. Sci. Eng. A 2006, 417, 334-340. [CrossRef]

22. Gill, A.; Telang, A.; Mannava, S.R.; Qian, D.; Pyoun, Y.-S.; Soyama, H.; Vasudevan, V.K. Comparison of mechanisms of advanced mechanical surface treatments in nickel-based superalloy. Mater. Sci. Eng. A 2013, 576, 346-355. [CrossRef]

23. Soyama, H. Comparison between the improvements made to the fatigue strength of stainless steel by cavitation peening, water jet peening, shot peening and laser peening. J. Mater. Process. Technol. 2019, 269, 65-78. [CrossRef]

24. SMS Committee on X-ray Study of Mechanical Behavior of Materials. Standard method for X-ray stress measurement. JSMS Stand. 2005, JSMS-SD-10-05, 1-21.

25. He, B.B.; Preckwinkel, U.; Smith, K. Advantage of using 2D detectors for residual stress measurements. Adv. X-ray Anal. 2000, $42,429-438$.

26. Takakuwa, O.; Soyama, H. Optimizing the conditions for residual stress measurement using a two-dimensional XRD method with specimen oscillation. Adv. Mater. Phys. Chem. 2013, 03, 8-18. [CrossRef]

27. Hill, M. The slitting method. In Practical Residual Stress Measurement Methods; Schajer, G.S., Ed.; John Wiley \& Sons, Inc.: Hoboken, NJ, USA, 2013; pp. 89-108.

28. ASTM E837-13a. Standard Test Method for Determining Residual Stresses by the Hole-Drilling Strain-Gage Method; ASTM: West Conshohocken, PA, USA, 2020.

29. Chighizola, C.R.; D'Elia, C.R.; Weber, D.; Kirsch, B.; Aurich, J.C.; Linke, B.S.; Hill, M.R. Intermethod comparison and evaluation of measured near surface residual stress in milled aluminum. Exp. Mech. 2021, in press. 
30. Hatamleh, O.; Rivero, I.V.; Swain, S.E. An investigation of the residual stress characterization and relaxation in peened friction stir welded aluminum-lithium alloy joints. Mater. Des. 2009, 30, 3367-3373. [CrossRef]

31. Correa, C.; de Lara, L.R.; Diaz, M.; Gil-Santos, A.; Porro, J.A.; Ocana, J.L. Effect of advancing direction on fatigue life of 316L stainless steel specimens treated by double-sided laser shock peening. Int. J. Fatigue 2015, 79, 1-9. [CrossRef]

32. Kallien, Z.; Keller, S.; Ventzke, V.; Kashaev, N.; Klusemann, B. Effect of laser peening process parameters and sequences on residual stress profiles. Metals 2019, 9, 655. [CrossRef]

33. Wang, Z.D.; Sun, G.F.; Lu, Y.; Chen, M.Z.; Bi, K.D.; Ni, Z.H. Microstructural characterization and mechanical behavior of ultrasonic impact peened and laser shock peened AISI 316L stainless steel. Surf. Coat. Technol. 2020, 385, 19. [CrossRef]

34. Bhamare, S.; Ramakrishnan, G.; Mannava, S.R.; Langer, K.; Vasudevan, V.K.; Qian, D. Simulation-based optimization of laser shock peening process for improved bending fatigue life of Ti-6Al-2Sn-4Zr-2Mo alloy. Surf. Coat. Technol. 2013, 232, 464-474. [CrossRef]

35. Correa, C.; de Lara, L.R.; Diaz, M.; Porro, J.A.; Garcia-Beltran, A.; Ocana, J.L. Influence of pulse sequence and edge material effect on fatigue life of Al2024-T351 specimens treated by laser shock processing. Int. J. Fatigue 2015, 70, 196-204. [CrossRef]

36. Keller, S.; Chupakhin, S.; Staron, P.; Maawad, E.; Kashaev, N.; Klusemann, B. Experimental and numerical investigation of residual stresses in laser shock peened AA2198. J. Mater. Process. Technol. 2018, 255, 294-307. [CrossRef]

37. Xu, G.; Luo, K.Y.; Dai, F.Z.; Lu, J.Z. Effects of scanning path and overlapping rate on residual stress of 316L stainless steel blade subjected to massive laser shock peening treatment with square spots. Appl. Surf. Sci. 2019, 481, 1053-1063. [CrossRef]

38. Sano, Y.; Akita, K.; Sano, T. A mechanism for inducing compressive residual stresses on a surface by laser peening without coating. Metals 2020, 10, 816. [CrossRef]

39. Pan, X.L.; Li, X.; Zhou, L.C.; Feng, X.T.; Luo, S.H.; He, W.F. Effect of residual stress on S-N curves and fracture morphology of Ti6Al4V titanium alloy after laser shock peening without protective coating. Materials 2019, 12, 3799. [CrossRef]

40. Busse, D.; Ganguly, S.; Furfari, D.; Irving, P.E. Optimised laser peening strategies for damage tolerant aircraft structures. Int. J. Fatigue 2020, 141, 12. [CrossRef]

41. Sun, R.J.; Keller, S.; Zhu, Y.; Guo, W.; Kashaev, N.; Klusemann, B. Experimental-numerical study of laser-shock-peening-induced retardation of fatigue crack propagation in Ti-17 titanium alloy. Int. J. Fatigue 2021, 145, 13. [CrossRef]

42. Soyama, H. Enhancing the aggressive intensity of a cavitating jet by introducing a cavitator and a guide pipe. J. Fluid Sci. Technol. 2014, 9, 1-12. [CrossRef]

43. Soyama, H. Enhancing the aggressive intensity of a cavitating jet by means of the nozzle outlet geometry. J. Fluids Eng. 2011, 133, 1-11. [CrossRef]

44. Nishikawa, M.; Soyama, H. Two-step method to evaluate equibiaxial residual stress of metal surface based on micro-indentation tests. Mater. Des. 2011, 32, 3240-3247. [CrossRef]

45. Naito, A.; Takakuwa, O.; Soyama, H. Development of peening technique using recirculating shot accelerated by water jet. Mater. Sci. Technol. 2012, 28, 234-239. [CrossRef]

46. ASTM E112-13. Standard Test Methods for Determining Average Grain Size; ASTM: West Conshohocken, PA, USA, 2020.

47. He, B.B. Two-Dimensional X-Ray Diffraction; John Wiley \& Sons, Inc.: Hoboken, NJ, USA, 2009; pp. 249-328.

48. Kumagai, M.; Curd, M.E.; Soyama, H.; Ungár, T.; Ribárik, G.; Withers, P.J. Depth-profiling of residual stress and microstructure for austenitic stainless steel surface treated by cavitation, shot and laser peening. Mater. Sci. Eng. A 2021, 813, 141037. [CrossRef] 